\title{
Power Stabilization by Windfarm Applied Statistical Model and Pumped Storage Generation Using Archimedean Screw
}

\author{
Hiroya Mitsuyose, Daichi Mizuse, Hiroatsu Fujiwara and Akira Sugawara \\ Department of Electrical and Electronic Engineering, Niigata University, Niigata 950-2181, Japan
}

\begin{abstract}
In this paper, a method of stabilizing electric power by a system which is a combination of wind power generation and pumped storage power generation is proposed. The system operates based on the output predicted value of the windfarm. When the measured windfarm output is larger than the predicted value, the system is pumping up water with surplus power. When the windfarm output is smaller than the predicted value, the system is filling up lack power by hydro generator. Also, since hydro generator works with a start-up delay time, output shortage occurs at this time. To improve output shortage at the time, we estimate the time below the predicted value by a statistical model. As the result, the system succeeded in stabilizing the power and improving the start-up delay time of the hydro generator.
\end{abstract}

Key words: Windfarm, pumped storage power generation, Archimedean screw, statistical model.

\section{Introduction}

In recent years, power generation methods of using natural energy have become popular in order to realize a low-carbon society. Wind power generation is one of these methods. But its output changes irregularly and leads to the instability of power system while wind power connects it directly [1]. Therefore, the wind power generation system generally stores energy in a battery, etc. [2]. However, the quantity of the stored energy in a battery has a limit, and the lifetime of the store equipment is not so long.

We propose a method of using a pumped storage power station for regulating power supply of 1,000 MW class windfarm [3, 4]. Pumped storage power station has advantages about the maximum amount of regulated power supply and lifetime of the facility. Moreover, it works from the start of power generation to the rating in short time of about $6 \mathrm{~min}$, and the output adjustment is easy.

Corresponding author: Akira Sugawara, Ph.D., associate professor, research fields: electric power engineering and high voltage engineering.
In this paper, it is assumed that the combination of a seawater pumped storage power station and offshore wind power generations, because there are many places where mountains of several hundred meters height are along the coast in Japan. Seawater pumped storage power can be reduced the construction cost of the lower reservoir. Also, offshore wind power generation can obtain large and stable electric power compared with land wind power.

In this paper, power generation system that combines offshore wind power and sea water pumped storage power is simulated.

There are many ways of short-term (a few minutes) of windfarm output. For example, An et al. [5] use Chaotic-Time-Series method and GM $(1,1)$ method, Zhu et al. [6] use Fuzzy Modeling method, and Peng et al. [7] use ANN (artificial neural network) method.

We need to predict the output after about 6 min to 20 min in order to determine the starting time of the hydro generator. Therefore, we predict short-term predictive value of windfarm and determine the starting time of the hydro generator using a statistical model. 


\section{Outline of This System}

\subsection{Wind and Pumped Storage Power System}

The schematic drawing of this system is shown in Fig. 1. This system shall be placed on a mountain close to the sea. A windfarm of 1,000 MW is installed on the mountain and/or offshore. In addition, an upper reservoir is installed in the slope of the mountain. The electricity of the wind power generations is sent to an electric power system. And the redundant electricity of the wind power generations is used for pumping.

The wind power generations and pumped storage power plant are connected to the power system. The pumped storage power system is constituted by the Archimedean screw that is pumping from lower reservoir to the upper pond and the hydro generator that is driven using the upper pond water.

\subsection{Archimedean Screw}

In this paper, we use the Archimedean screw as a water pump. When the wind stops, the wind turbines cannot generate electricity. Therefore, conventional water pumps cannot pump up water stably. On the other hand, the Archimedean screw can hold water inside the screws when the power is stopped and can pump up water immediately when the power is supplied. So, it is suitable for intermittent operation as this system.

A model of the Archimedean screw is shown in Fig. 2. And, specifications of the Archimedean screw in this research are shown in Table 1 . We consider that the Archimedean screw is not only rotating the screw, but

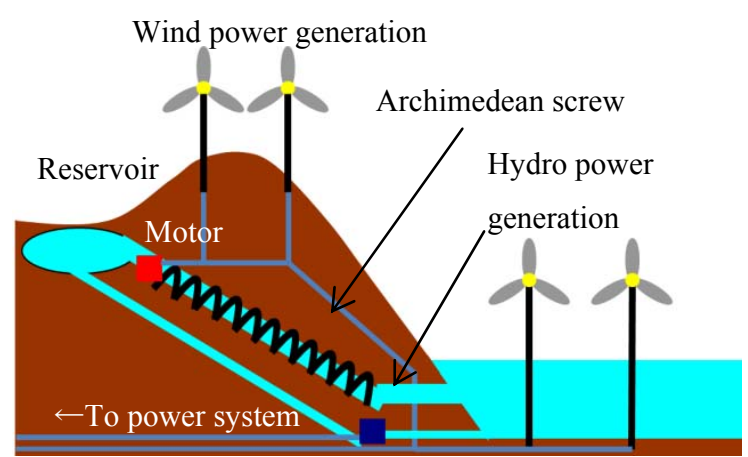

Fig. 1 Schematic drawing of wind and pumped storage power system.

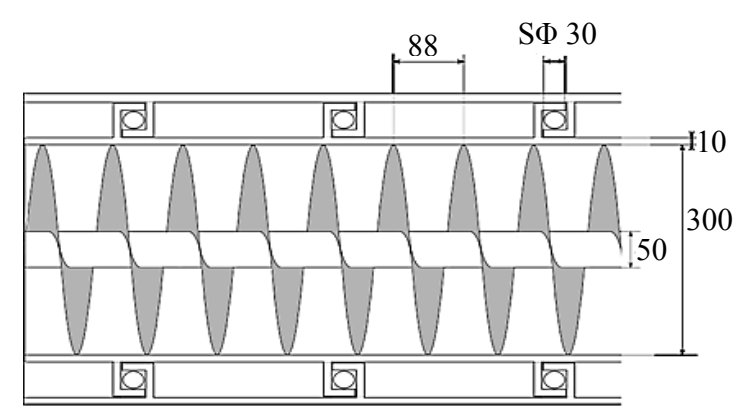

Unit: [Centimeter]

Fig. 2 Schematic drawing of the Archimedean screw.

Table 1 Specifications of the Archimedean screw in this research.

\begin{tabular}{ll}
\hline Number of screw period & 455 cycle \\
\hline Screw diameter & $3 \mathrm{~m}$ \\
Screw length & $400 \mathrm{~m}$ \\
Screw angle & $30 \mathrm{deg}$ \\
Screw mass & $250.7 \mathrm{t}$ \\
Rated speed & $25 \mathrm{rpm}$ \\
Effective head & $200 \mathrm{~m}$ \\
Pumping amount & $3.17 \mathrm{~m}^{3} / \mathrm{s}$ \\
Moment of inertia & $282,000 \mathrm{~kg} \cdot \mathrm{m}^{2}$ \\
\hline
\end{tabular}

the screw with the cylinder, outer frame of the screw. It is a costly, but it is possible to prevent deterioration due to friction between the trough and the screw and to smoothly rotate by outside fixed trough and bearings.

\subsection{Operating Method of This System}

This system operates based on the output predicted value of the windfarm. When the measured windfarm output is larger than the predicted value, the system is pumping up water with surplus power. When the measured value is smaller than the predicted value, the system is filling up lack power by hydro generator. The outline of the operating method is shown in Fig. 3.

\section{Simulation}

\subsection{Simulation Method}

Sample output data of a $2 \mathrm{MW}$ wind turbine at intervals of one second from 13:00 to 16:00 on September 20, 2011 are shown in Fig. 4. Also, the outline of windfarm in this paper is shown in Fig. 5. It is assumed to be placed 20 turbines in vertical to the wind 


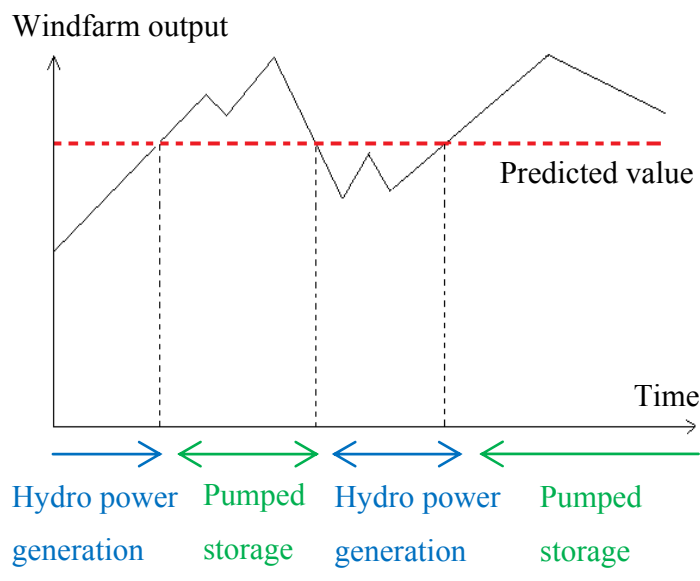

Fig. 3 Outline of operating method.

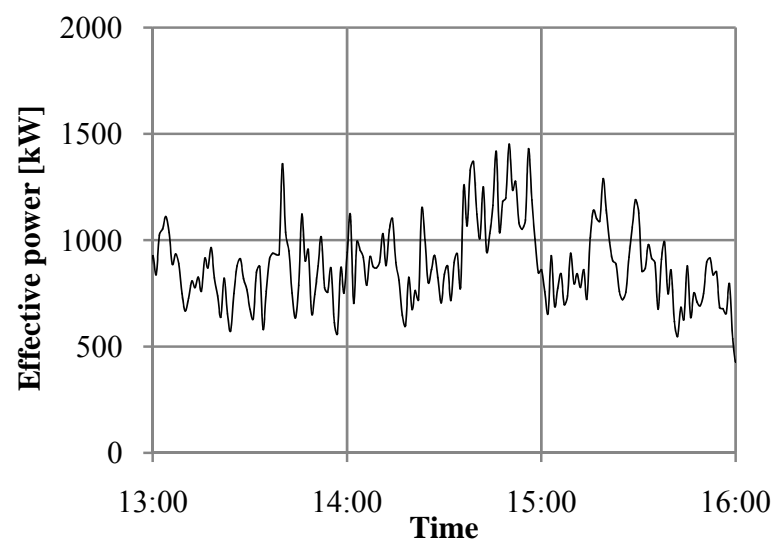

Fig. 4 Output data of the $2 \mathrm{MW}$ wind power generator.

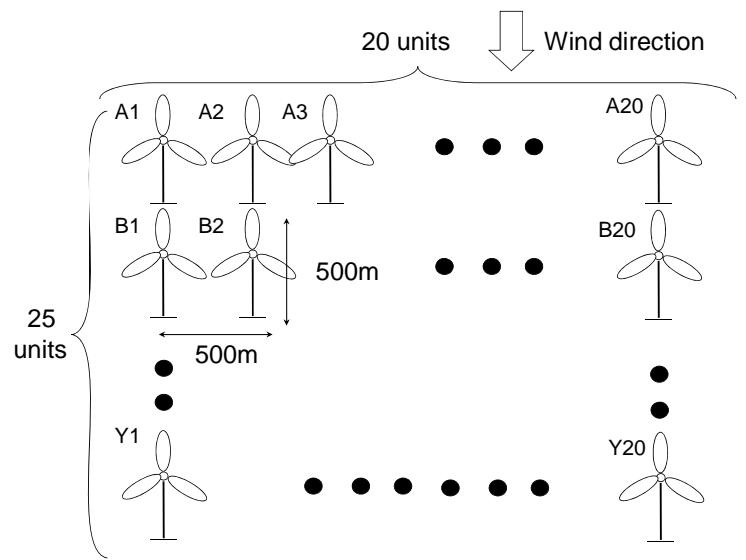

Fig. 5 Diagram of the windfarm.

direction and 25 turbines in parallel. We calculate the windfarm output from single wind power output data of Fig. 4.

We suppose that wind blows vertical to the line from A1 to A20. The average wind velocity from 13:00 to

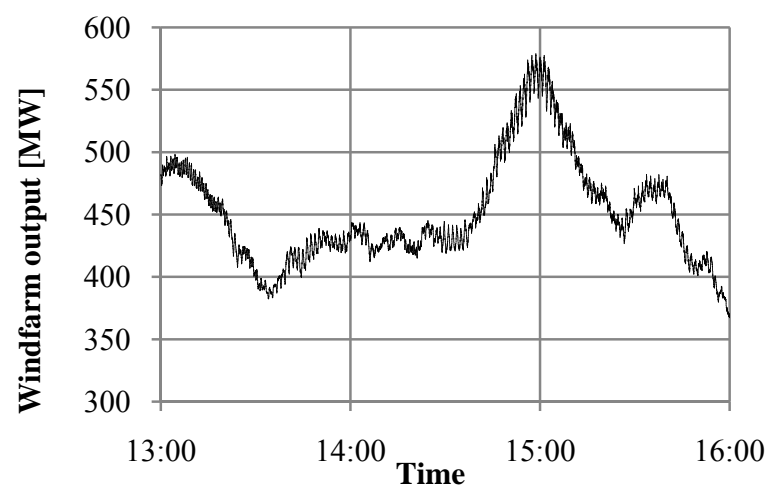

Fig. 6 Output of the windfarm.

16:00 is $6.3 \mathrm{~m} / \mathrm{s}$. The wind which has observed at line A will reach line B 78 seconds later because the distance between line A and B is $500 \mathrm{~m}$. As a result, the output of the windfarm is shown in Fig. 6.

\subsection{Simulation Model}

In this simulation, it is assumed to take $350 \mathrm{~s}$ to start the hydro generator. So, lack power occurs for the start-up delay time of the hydro generator, because after the measured value of the windfarm output is below the predicted value, the hydro generator starts.

In this paper, we predict the windfarm output using a statistical model, and the hydro power generator starts up before the windfarm output is below the predicted value. In particular, we calculate the correlation coefficient in order to determine the state of the correlation of windfarm output. The correlation coefficient takes a value from -1 to +1 ; it indicates positive correlation or negative one when the value is positive or negative, respectively. Therefore, if it shows the negative correlation coefficient, the output is lowered, it is estimated that the future of the output is also down. In this case, by using the least squares method, the time below the predicted value is estimated, then the starting time of the hydro generator is set at minus $350 \mathrm{~s}$ from the estimated time. The correlation coefficient is given by the following equation.

$$
r=\frac{s_{x y}}{s_{x} s_{y}}
$$

where, $s_{x}$ and $s_{y}$ show a standard deviation, $s_{x y}$ shows a covariance. 


$$
\begin{gathered}
s_{x}=\sqrt{\frac{1}{n-1} \sum_{i=1}^{n}\left(x_{i}-\bar{x}\right)^{2}} \\
s_{y}=\sqrt{\frac{1}{n-1} \sum_{i=1}^{n}\left(y_{i}-\bar{y}\right)^{2}} \\
s_{x y}=\frac{1}{n-1} \sum_{i=1}^{n}\left(x_{i}-\bar{x}\right)\left(y_{i}-\bar{y}\right)
\end{gathered}
$$

where, $\bar{x}$ and $\bar{y}$ show the average value of data $x$ and $y$, respectively. In this calculation, $x$ and $y$ are calculated as time and output of windfarm, respectively.

\subsection{Fourier Transform}

Because windfarm output is a vibrating waveform, it may not be obtained an appropriate correlation coefficient affected by detail variation component of the output, if number of data $n$ is small. In this paper, the output waveform is approximated by using Fourier transform. The Fourier transform of the windfarm output is shown in Fig. 7.

\subsection{Simulation Conditions}

Table 2 shows conditions for the simulation. It is assumed that the windfarm output is rating of 1,000 MW, i.e., arranged as Fig. 5 for 500 wind turbines of the rating of $2 \mathrm{MW}$, and the average prediction value of windfarm output is 455 MW. Three hydro generators of $30 \mathrm{MW}$, the total rating of $90 \mathrm{MW}$, and five the Archimedean screws of the rating of $11 \mathrm{MW}$ and the maximum consumption are assumed. The model of pumped hydro power station is Okinawa Yanbaru Seawater Pumped Storage Power Station.

\subsection{Simulation Result}

First, Fig. 8 shows calculation result of the correlation coefficient of the windfarm output.

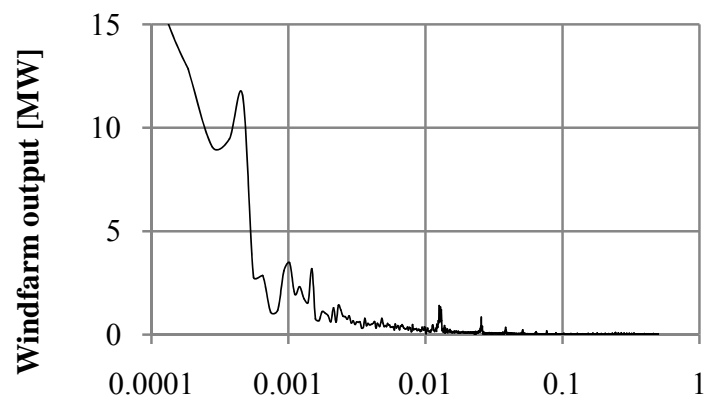

Frequency [Hz]

Fig. 7 Fourier transform of the windfarm output.

Table 2 Conditions for the simulation.

\begin{tabular}{|l|l|}
\hline Wind power generators & $\begin{array}{l}\text { Rated: } 2 \mathrm{MW} \times 500 \text { Units }= \\
1,000 \mathrm{MW}\end{array}$ \\
\hline $\begin{array}{l}\text { Predicted value of } \\
\text { windfarm output }\end{array}$ & $455 \mathrm{MW}$ \\
\hline Hydro power generators & $\begin{array}{l}\text { Rated: } 30 \mathrm{MW} \times 3 \text { Units }=90 \\
\text { MW } \\
\text { Start-up time: } 350 \mathrm{~s}\end{array}$ \\
\hline $\begin{array}{l}\text { Archimedean screws } \\
\text { power consumption }\end{array}$ & $\begin{array}{l}\text { Rated: } 11 \mathrm{MW} \times 5 \text { Units }=55 \\
\mathrm{MW} \\
\mathrm{Max}: 21 \mathrm{MW} \times 5 \text { Units }=105 \\
\mathrm{MW}\end{array}$ \\
\hline
\end{tabular}
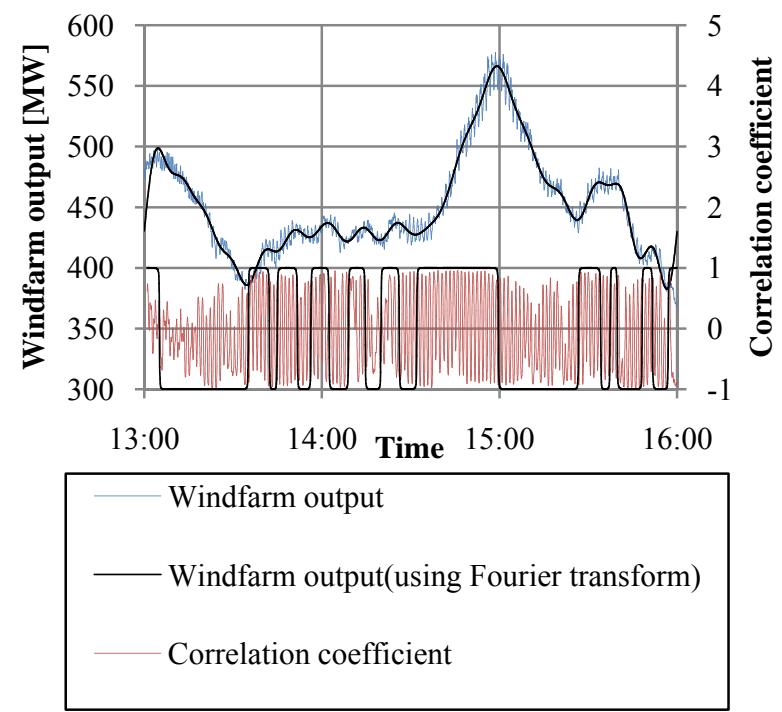

Fig. 8 Calculation of correlation coefficient of the windfarm output.

In this paper, we calculate the correlation coefficient for the past $60 \mathrm{~s}$ based on the certain time. Therefore, $n$ is 60 in Eqs. (2)-(4).

As the result, it can be confirmed that the appropriate correlation coefficient is obtained by using Fourier transform to windfarm output. 


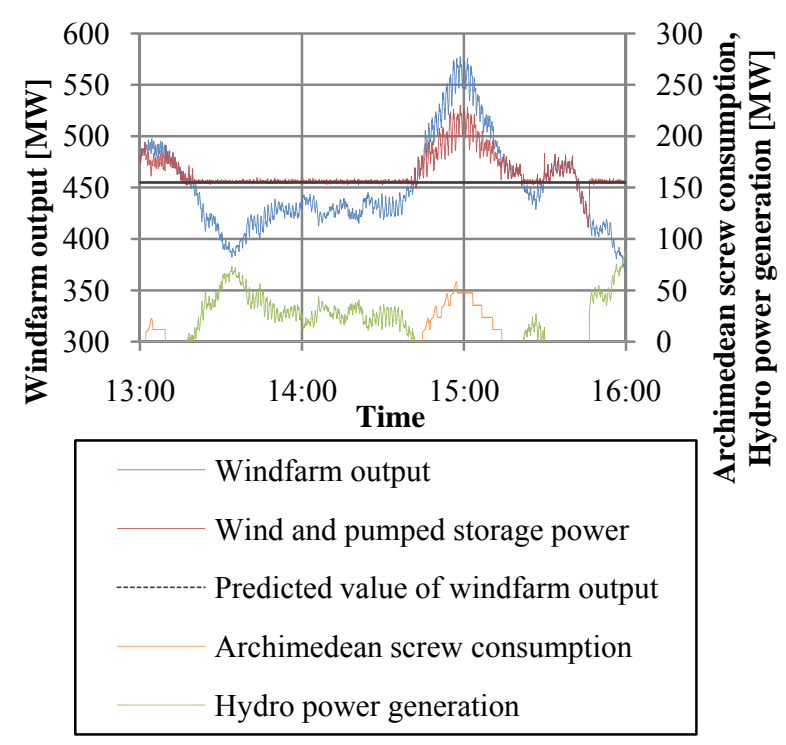

Fig. 9 Simulation result.

Next, Fig. 9 shows a result of the simulation of the system. It is found to stabilize the system output, because it can be adjusted the excess and deficiency of output by pumped storage power.

Also, for this result, we consider the frequency variation value. Frequency variation of a power system can be obtained from power fluctuation value and total amount of the power system as follows [8].

$$
\Delta f=\frac{\frac{\Delta P}{P} \times 100}{K_{G}+K_{L}}[\mathrm{~Hz}]
$$

where, $\Delta P$ is power fluctuation value (MW), $P$ is total amount of the power system (MW), $K_{G}$ and $K_{L}$ are frequency characteristics of power and load, respectively. $P$ is a value of $6,440-13,950 \mathrm{MW}$ referring the total amount of power generation by the Tohoku-Electric Power Co., Inc. in 2014. $K_{G}+K_{L}$ is a value $7-10$, generally. In this calculation, by assuming the worst-case, we select that $P$ is $6,440 \mathrm{MW}$ and $K_{G}+$ $K_{L}$ is 7 . Table 3 shows this calculation result.

As the result, in the case of wind power generation only, power fluctuation value is $-88:+123 \mathrm{MW}$, frequency variation of power system is $-0.137:+0.191$ Hz. On the other hand, in the case of wind and pumped storage power generation, power fluctuation value is
Table 3 Conditions for the simulation.

\begin{tabular}{lll}
\hline & Wind power & $\begin{array}{l}\text { Wind and pumped } \\
\text { storage power }\end{array}$ \\
\hline $\begin{array}{l}\text { Power } \\
\text { fluctuation } \\
\text { value }(\mathrm{MW})\end{array}$ & $-88:+123$ & $-45:+76$ \\
$\begin{array}{l}\text { Frequency } \\
\text { variation }(\mathrm{Hz})\end{array}$ & $-0137:+0.191$ & $-0.070:+0.118$ \\
\hline
\end{tabular}

Table 4 The results of hydro power generator start-up. Start-up time: 350 s

\begin{tabular}{lll}
\hline $\begin{array}{l}\text { Time below } \\
\text { the predicted } \\
\text { windfarm output }\end{array}$ & $\begin{array}{l}\text { Time obtained } \\
\text { hydro power } \\
\text { generator output }\end{array}$ & Delay time \\
\hline \begin{tabular}{lll}
$(1) \quad 13: 19: 03$ & $13: 17: 52$ & None \\
$(2) \quad 15: 21: 52$ & $15: 17: 12$ & None \\
$(3) \quad 15: 41: 54$ & $15: 45: 40$ & $226 \mathrm{~s}$ \\
\hline$-45:+76 \quad$ MW, frequency variation of power is &
\end{tabular} \\
$-0.070:+0.118 \mathrm{~Hz}$.
\end{tabular}

Therefore, it is possible to stabilize power by wind and pumped storage power system. The Tohoku-Electric Power Co., Inc. sets a target value of frequency variation within $\pm 0.2 \mathrm{~Hz}$, possibility to deviate from the target increases if wind power only is connected to the power system. Thus, it can be seen that this combined system of the large windfarm and pumped storage hydro power generation greatly improves the situation.

Also, Table 4 shows the results of hydro power generator start-up.

As the result, for time (1) and (2), the start-up delay time of hydro power generator is eliminated, and for the time (3), it is succeeded that the start-up time is reduced approximately 30\% compared with $350 \mathrm{~s}$. However, the start-up delay time at the time (3) cannot be eliminated, because the windfarm output is below the predicted output within $350 \mathrm{~s}$ after the negative correlation is detected. To deal with the case of time (3), it is necessary to consider how to set the appropriate output predicted value.

\section{Conclusions}

In this paper, we proposed a method of stabilizing by the power system which was a combination of wind power generation and pumped storage power 
generation with the Archimedean screw, and simulated about the stability of the power system. As the result, it was found that the power system was stabilized and the requirement in the Tohoku-Electric Power Co, Inc. was achieved.

In addition, we succeeded in improving the start-up delay time of the hydro-generator by using the statistical model for the system. However, delay time always occurred in the cases that the windfarm output was below the predicted output within $350 \mathrm{~s}$ after the negative correlation was detected. So, it will be necessary to consider how to set the appropriate output predicted value.

\section{Acknowledgments}

This work was supported by JSPS KAKENHI Grant Number 25420246. We say thanks to Niigata Prefecture office to provide data about the start-up characteristics of hydro power generator.

\section{References}

[1] Endegnanew, A. G., Farahmand, H., and Hernando, D. H. 2013. "Frequency Quality in the Nordic Power System: Wind Variability, Hydroelectric Power Pump Storage and Usage of HVDC Links." Energy Procedia 35: 62-8.

[2] Ma, T., Yang, H. X., and Lu, L. 2014. "Feasibility Study and Economic Analysis of Pumped Storage and Battery Storage for a Renewable Energy Powered Island." Energy Conversion and Management 79: 387-97.

[3] Sugawara, A., Nishizima, K., and Mitobe, M. 2011. "Power Stabilization of Large-Scale Wind Power Generation by Pumped-up Hydro Power Generation with Archimedean Screw." Presented at the Clean Technology 2011, Renewable Energy Technologies: WE8.853, Boston, USA.

[4] Zhai, Y. Z., Ma, J. H., Mitobe, M., Uehara, S., Gon, S. Y., and Sugawara, A. 2013. "A New Strategy of Using Unstable Offshore Wind Power by Combination with Pumped Storage Generation with Reversible Pump Turbine." Presented at the 6th Annual Cleantech Conference, Washington DC, USA.

[5] An, X. L., Jiang, D. X., Liu, C., and Zhao, M. H. 2011. "Windfarm Power Prediction Based on Wavelet Decomposition and Chaotic Time Series." Expert System with Application 38: 11280-5.

[6] Zhu, B., Chen, M. Y., Wade, N., and Ran, L. 2012. "A Prediction Model for Windfarm Power Generation Based on Fuzzy Modeling." Procedia Environmental Sciences 12: 122-9.

[7] Peng, H. W., Liu, F. R., and Yang, X. F. 2013. "A Hybrid Strategy of Short Term Wind Power Prediction." Renewable Energy 50: 590-5.

[8] Uehara, S., Nishizima, K., Mitobe, M., Ma, J. H., Zhai, Y. Z., Gon, S. Y., and Sugawara, A. 2012. "Stabilization of Large-Scale Wind Power Generation by Combination of Pumped Storage Generation with Archimedean Screw." Presented at the 2012 Asian Pacific Conference on Energy, Environment and Sustainable Development, Kuala Lumpur, Malaysia. 